\title{
Dual-release hydrocortisone vs conventional glucocorticoids in adrenal insufficiency
}

\author{
V Guarnotta, C Di Stefano, A Santoro, A Ciresi, A Coppola and C Giordano \\ Dipartimento di Promozione della Salute, Materno - Infantile, Medicina Interna e Specialistica di Eccellenza 'G. D'Alessandro' (PROMISE), Sezione di \\ Malattie Endocrine, del Ricambio e della Nutrizione, Università di Palermo, Palermo, Italy
}

Correspondence should be addressed to C Giordano: carla.giordano@unipa.it

\begin{abstract}
Background: Dual-release hydrocortisone (DR-HC) improves metabolism in patients with adrenal insufficiency. The aims of this study were to compare the cardiovascular and metabolic effects of conventional glucocorticoids (GCS) vs. DR-HC and of high vs. low doses of GCs, after 48 months of observation.

Methods: We selected 27 patients on hydrocortisone (mean dose $17.5 \pm 4.2 \mathrm{mg} /$ day) and 20 patients on cortisone acetate (mean dose $37.5 \pm 12.1 \mathrm{mg} / \mathrm{day}$ ) who maintained this treatment (group A) and 53 patients switched to DR-HC (mean dose $22 \pm 4.8 \mathrm{mg} /$ day) (group B). At baseline and after 48 months, clinical and metabolic parameters and Framingham Risk Score (FRS) were obtained.

Results: After 48 months, patients in group A had a significant increase from baseline in BMI $(P<0.001)$, waist circumference $(P=0.001)$, systolic blood pressure $(P=0.001)$, LDL cholesterol $(P=0.018), \mathrm{HbA} 1 \mathrm{c}(P=0.020)$ and FRS $(P=0.002)$. By contrast, patients in group B had a significant decrease in BMI $(P=0.002)$, waist circumference $(P=0.015)$, diastolic blood pressure $(P=0.031)$, total $(P=0.006)$ and LDL cholesterol $(P=0.005)$, HbA1c $(P<0.001)$ and FRS $(P=0.015)$ compared to baseline. No significant differences between high and low doses of both conventional GCs and DR-HC were observed. Conclusions: DR-HC is associated with an improvement of metabolic parameters and cardiovascular risk compared to conventional GCs, which are associated with a worsening of these parameters, regardless of the dose used.
\end{abstract}

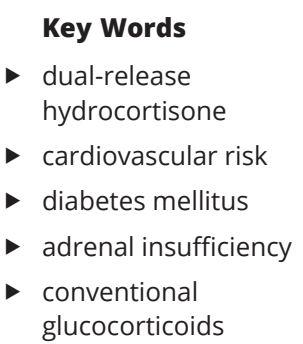

Endocrine Connections (2019) 8, 853-862

\section{Introduction}

Adrenal insufficiency (AI) is characterized by high morbidity and mortality, likely due to inappropriate glucocorticoid (GC) treatment and no physiological daily exposure. Indeed, conventional GC treatment, with hydrocortisone (HC) or cortisone acetate, requires twothree daily doses to maintain adequate plasma cortisol levels, with the highest dose administered in the morning and a lower dose in the afternoon or, if required, in the evening (1), exposing patients to supraphysiological levels of cortisol. Overexposure to GCs has been demonstrated to increase metabolic dysfunction and cardio metabolic risk and cause a sleep pattern disturbance, resulting in impaired quality of life and enhancing mortality and morbidity $(2,3)$.

Once-daily dual-release hydrocortisone (DR-HC) has been demonstrated to provide a cortisol exposure-time profile close to the physiological one. It is characterized by an immediate-release fraction of HC in the outer layer of the tablet and an extended-release fraction in the core, able to provide an adequate concentration of cortisol within $50 \mathrm{~min}$ of administration, half-cortisol plasma concentration for $6 \mathrm{~h}$ thereafter and a minimal cortisol level 18-24hours after intake (4). This characteristic formulation has been shown to improve anthropometric

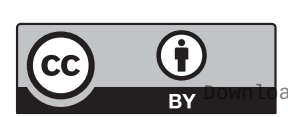

This work is licensed under a Creative Commons Attribution 4.0 International License. ded from Bioscientifica.com at 04/26/2023 10:25:28AM 
and metabolic parameters and quality of life, appearing to be safe in the long term $(5,6,7,8,9,10)$.

The primary objective of the current study was to compare the effects of DR-HC and conventional GCs in patients with $\mathrm{AI}$, on anthropometric parameters, glucose and lipid metabolism, and cardiovascular risk estimated by the FRS for non-diabetic patients (11) and the United Kingdom Prospective Diabetes Study (UKPDS) risk engine for diabetic patients (12), after 48 months of treatment. Secondary objective was evaluating the differences in anthropometric and metabolic parameters between patients treated with high and low doses of both conventional GCs and DR-HC at 48 months.

\section{Materials and methods}

\section{Study participants}

We evaluated data from 100 consecutive patients, 44 with PAI and 56 with SAI due to hypopituitarism, out of a total of 140 patients who were on conventional GC treatment. Patients were consecutively referred to the Division of Endocrinology of Palermo University from January 2008 to December 2013. Specifically, we carefully selected data of 47 patients who were on conventional GC treatment (20 on cortisone acetate and 27 on HC), administered twice or three times a day, and maintained this therapy (group A) and 53 patients who were switched from conventional GC treatment (15 on cortisone acetate and 38 on HC) to DR-HC (group B) administered orally in the morning in a fasting state, for a 48-month period. Out of the 40 patients excluded from the study, 30 patients did not meet the inclusion criteria, while 10 were lost to follow-up (Fig. 1). The switch to DR-HC was judged to be appropriate on clinical grounds in those patients who complained of fatigue and weakness, presented hyponatremia $(<134 \mathrm{mmol} / \mathrm{L})$ or hypoglycemia $(\leq 2.78 \mathrm{mmol} / \mathrm{L})$ or showed more than two comorbidities such as diabetes, osteoporosis/osteopenia, hypertension and central obesity. The switch from HC to DR-HC was made with an equivalent, while the dose was reduced from cortisone acetate to DR-HC taking into consideration the minor GC activity of cortisone acetate compared to HC and patients' clinical characteristics.

All patients had disease duration of at least 5 years. Inclusion criteria were the following: age 18-75 years; diagnosis of AI; ongoing daily conventional GC treatment for at least 5 years. Exclusion criteria were pregnancy and lactation and AI secondary to adrenocortical carcinoma.

AI was diagnosed as recommended by international guidelines (13). Diagnosis of diabetes was made according to the ADA guidelines (14).

Overall, 44 patients had PAI, 31 with autoimmune polyglandular syndrome (APS) and 13 with isolated autoimmune AI (Table 1). Patients with celiac disease were

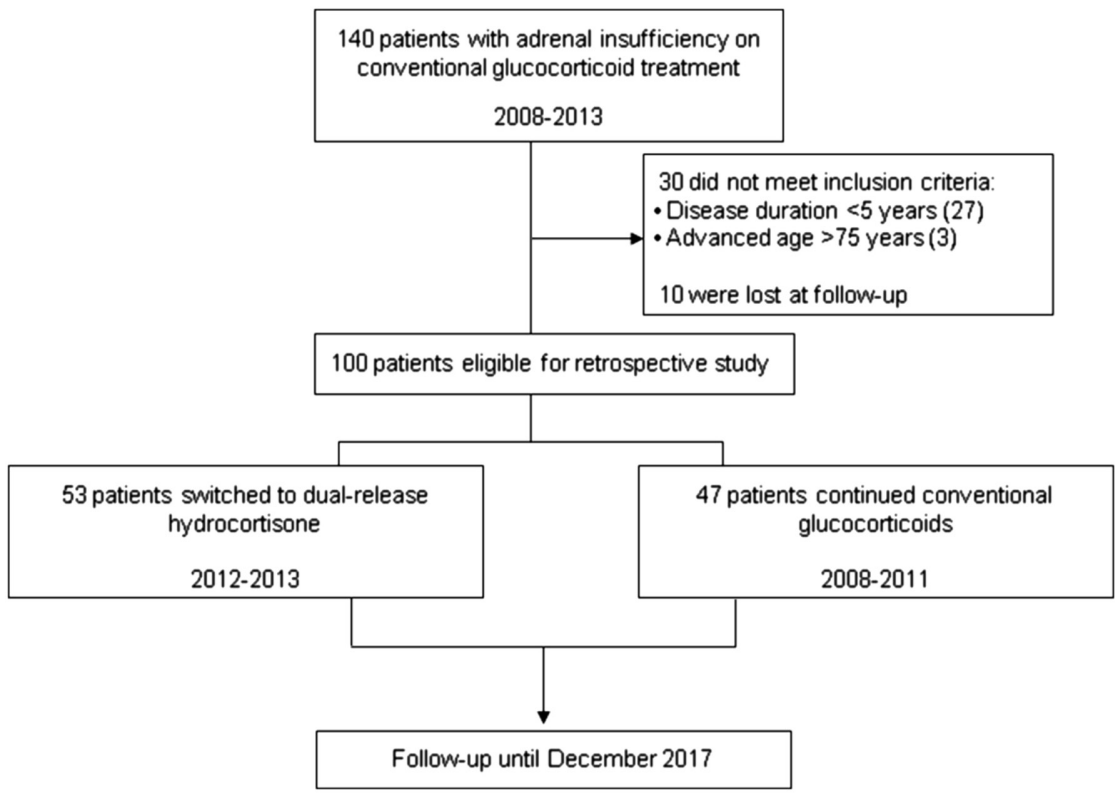

Figure 1

Flow chart of patient enrolment during the 48-month period of observation. (c) 2019 The authors Published by Bioscientifica Ltd

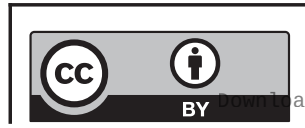

This work is licensed under a Creative Commons Attribution 4.0 International License. ded from Bioscientifica.com at 04/26/2023 10:25:28AM via free access 
Table 1 Distribution of patients with adrenal insufficiency.

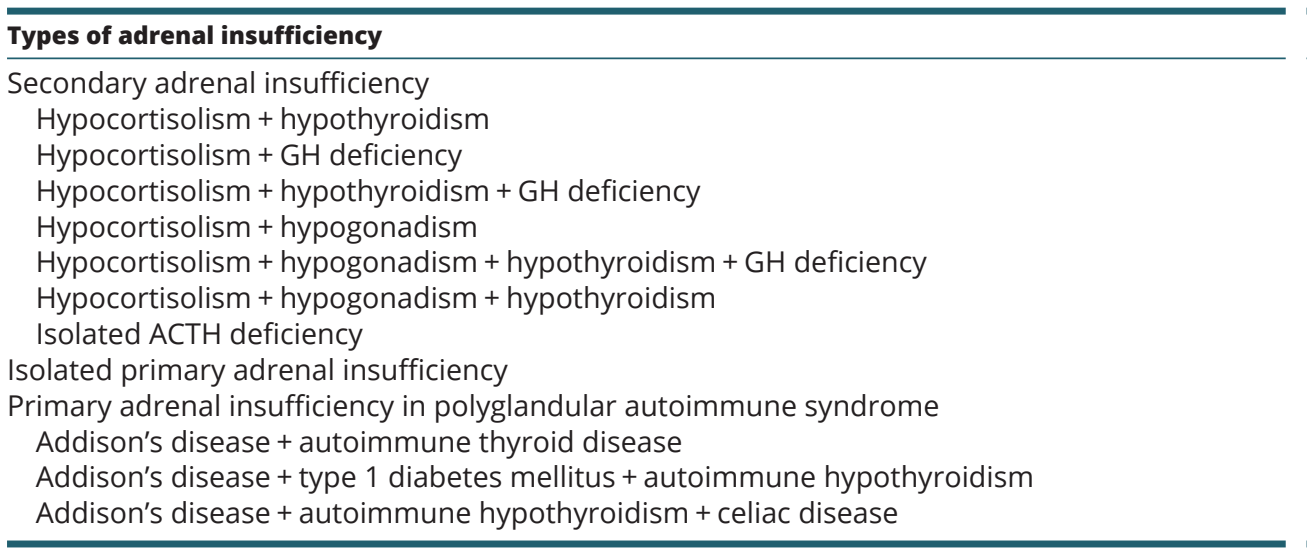

\begin{tabular}{c}
\hline Cases $($ No. $=100)$ \\
\hline 12 \\
11 \\
10 \\
8 \\
7 \\
4 \\
4 \\
11 \\
11 \\
10 \\
10
\end{tabular}

on a stable gluten-free diet. Patients with PAI were also on stable treatment with fludrocortisone $(0.05-0.1 \mathrm{mg} /$ day, once). Among patients with APS and type 1 diabetes, four were in group A and six in group B.

The characteristics of patients with SAI and the other endocrine deficiency combinations are shown in Table 1. Patients with hypothyroidism were treated with levothyroxine at the average dose of $1 \mu \mathrm{g} / \mathrm{kg}$. Patients with GHD were treated with somatotropin at the average dose of $0.4 \mathrm{mg} /$ day. Males with hypogonadism were treated with an average dose of monthly injection of testosterone enanthate $250 \mathrm{mg}$. Premenopausal females were treated with a low dose of estrogen and progesterone therapy. No history of chronic GC use before substitutive treatment was known for patients with SAI.
All patients with SAI were on stable replacement treatment for the other deficiencies and maintained good and stable hormonal control during the whole follow-up. At baseline and after 48 months of DR-HC, respectively they had IGF-1 levels $137.5 \pm 25.6$ and $154.5 \pm 29.6 \mathrm{ng} /$ $\mathrm{mL}$, FT4 levels $1.26 \pm 0.36$ and $1.19 \pm 0.27 \mathrm{ng} / \mathrm{dL}$, total testosterone $5.1 \pm 1.6$ and $5.7 \pm 1.75 \mathrm{ng} / \mathrm{dL}$ (males) and total estrogens $104.2 \pm 35.8$ and $121 \pm 28.2 \mathrm{pg} / \mathrm{mL}$ (females). Fourteen patients with SAI had type 2 diabetes (four in group A and ten in group B).

During the 48-month treatment period, the conventional GC and the DR-HC doses were changed based on the physician's judgment of a patient's need in both groups of patients (Table 2). Each patient received instructions for treatment in special or emergency

Table 2 Dose adjustments according to the physician's judgment during the 48 months of conventional glucocorticoid and dual-release hydrocortisone treatments.

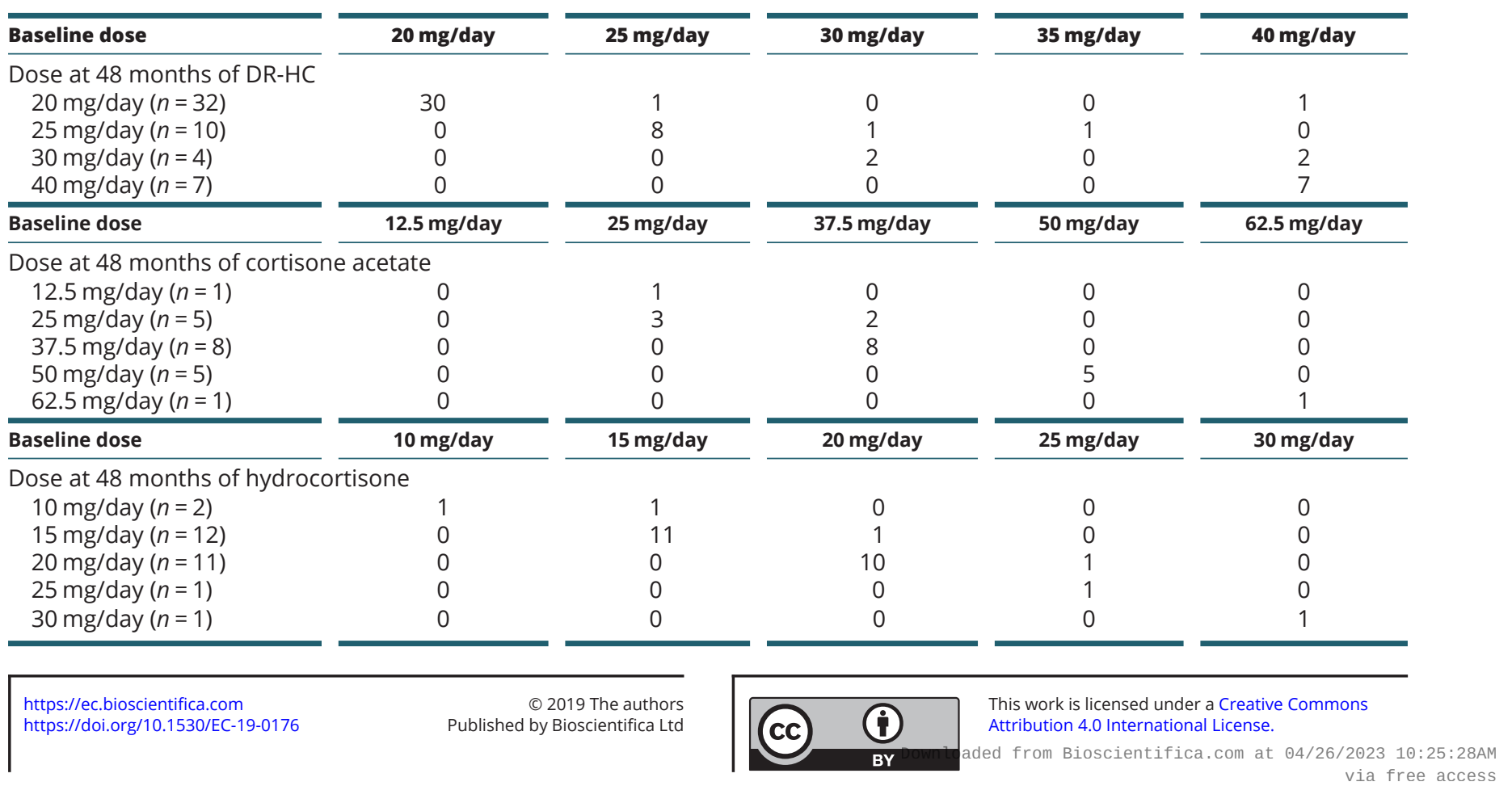


situations. Patients treated with DR-HC were instructed to add a rescue dose of HC during an intercurrent illness or stress (5 or $10 \mathrm{mg}$ according to severity of stress and symptoms).

The effects of the different doses of conventional GCs and DR-HC on metabolic parameters were also evaluated in all patients. However, only a minority of patients, 5/47 (11\%) in group A and 8/53 (15\%) in group B had their dose changed (Table 2) and no differences were found with the change in dosage (data not shown).

This study was carried out in accordance with the recommendations of the Paolo Giaccone Policlinico ethics committee with written informed consent from all subjects. All subjects gave written informed consent in accordance with the Declaration of Helsinki. The protocol was approved by the Paolo Giaccone Policlinico Ethics Committee.

\section{Study design}

At baseline and after 48 months of conventional GCs and DR-HC treatment, clinical and metabolic parameters were extracted from our archive.

Anthropometric parameters such as BMI, systolic and diastolic blood pressure (SBP and DBP) and WC, measured at the midpoint between the lower rib and the iliac crest, were extracted. In addition, fasting lipids (total cholesterol (TC), HDL cholesterol (HDL-C), LDL cholesterol (LDL-C) and triglycerides (TG)), HbA1c and glycemia were obtained. The blood sample was performed about $2 \mathrm{~h}$ after GC administration (patients took the dose in the morning on waking) to avoid patients experiencing fatigue or other symptoms due to the delayed intake of the drug.

In patients with type 1 diabetes mellitus, the insulin requirement was calculated as total daily, basal and prandial insulin (U/day).

The FRS for estimating the 10-year risk for cardiovascular events was calculated on the basis of age, sex, total and HDL cholesterol, blood pressure and smoking status for 80 patients with normal glucose tolerance, while the UKPDS risk engine was calculated for 14 patients with type 2 diabetes mellitus. Six non-diabetic patients aged $<30$ years were excluded for estimation of FRS.

\section{Assays}

Insulin, glycemia, HbA1c and lipids were measured with standard methods (Modular P800, Roche). LDL-C levels were calculated using the Friedewald formula $(\mathrm{TC}-(\mathrm{HDL}+(\mathrm{TG} / 5)))$.
The conversion factors for the International System (SI) were as follows: glucose $\mathrm{mg} / \mathrm{dL}$ vs $\mathrm{mmol} / \mathrm{L}: 0.0555$; TC and HDL-C mg/dL vs mmol/L: 0.0259; TG mg/dL vs mmol/L: 0.0113; HbA1c \% vs mmol/mol: 10.93-23.5\%.

\section{Statistical analysis}

The Statistical Packages for Social Science SPSS version 19 (SPSS, Inc., IBM) were used for data analysis. The normality of quantitative variables was tested with the ShapiroWilk test. The baseline characteristics of the groups were presented as mean \pm s.D. for continuous variables, while the rates and proportions were calculated for categorical data. The differences between the final and baseline data were evaluated with paired $t$-tests in a single group for quantitative variables and $\chi^{2}$ for categorical variables. The differences between the independent samples from groups $\mathrm{A}$ and $\mathrm{B}$ at 48 months were evaluated using the Student's $t$-test. The differences between patients treated with high and low doses of GCs and between patients divided by disease etiology (PAI and SAI) are presented as mean \pm s.D. A $P$ value $<0.05$ was considered statistically significant.

\section{Results}

The baseline characteristics of all patients with AI and subgroups (A and B) are shown in Table 3. During the 48-month period of observation 3 out of 47 patients had an adrenal crisis in group A $(0.06 \%)$ and none in the group B.

At baseline, no differences between groups A and B were observed with regard to the etiology of AI, percentage of arterial hypertension, visceral obesity and hypercholesterolemia, duration of disease, anthropometric parameters, lipids and glycaemia (Table 3). However, patients in group $B$ had a higher prevalence of osteoporosis/ osteopenia $(P<0.001)$, diabetes $(P=0.044)$, lower sodium $(P=0.001)$ and higher HbA1c levels $(P=0.002)$, than group A (Table 4).

After 48 months of observation, patients in group A had a significant increase in BMI $(P<0.001)$, WC $(P=0.001)$, SBP $(P=0.001)$, LDL-C $(P=0.018)$ and HbA1c $(P=0.020)$ (Table 4$)$. By contrast, patients in group B had a significant decrease in BMI $(P=0.002)$, WC $(P=0.015)$, DBP $(P=0.031)$, TC $(P=0.006)$, LDL-C $(P=0.005)$ and HbA1c $(P<0.001)$ (Table 4$)$.

At 48 months of treatment lower values of WC $(P=0.020), \quad$ SBP $\quad(P=0.001), \quad$ TC $\quad(P=0.005), \quad$ LDL-C 
Table 3 General characteristics of all patients and subgroups A and B at baseline.

\begin{tabular}{|c|c|c|c|c|}
\hline & All & Group A & Group B & \\
\hline & Baseline (No. $=100)$ & Baseline (No. $=47)$ & Baseline (No. $=53$ ) & \\
\hline & Subjects (\%) & Subjects (\%) & Subjects (\%) & $\boldsymbol{P}^{\mathbf{a}}$ \\
\hline \multicolumn{5}{|l|}{ Gender } \\
\hline Male & $32(32 \%)$ & $15(31.9 \%)$ & $17(32.1 \%)$ & 0.986 \\
\hline Female & $68(68 \%)$ & $32(68.1 \%)$ & $36(67.9 \%)$ & \\
\hline Primary adrenal insufficiency (PAI) & $44(44 \%)$ & $18(38.3 \%)$ & $26(49.1 \%)$ & 0.371 \\
\hline Secondary adrenal insufficiency (SAI) & $56(56 \%)$ & $29(61.7 \%)$ & $27(50.9 \%)$ & 0.731 \\
\hline Arterial hypertension & $29(29 \%)$ & $14(29.8 \%)$ & $15(28.3 \%)$ & 0.870 \\
\hline Osteoporosis/osteopenia & $40(40 \%)$ & $10(21.3 \%)$ & $30(56.6 \%)$ & $<0.001$ \\
\hline Visceral obesity & $71(74 \%)$ & $25(53.1 \%)$ & $46(86.7 \%)$ & 0.125 \\
\hline Hypercholesterolemia & $31(31 \%)$ & $8(17 \%)$ & $23(43.4 \%)$ & 0.073 \\
\hline Diabetes & $24(24 \%)$ & $8(17 \%)$ & $16(30.1 \%)$ & 0.044 \\
\hline \multicolumn{5}{|l|}{ Replacement therapy at run-in } \\
\hline Cortisone acetate & $56(56 \%)$ & $20(42.5 \%)$ & $31(67.9 \%)$ & 0.082 \\
\hline \multirow[t]{2}{*}{ Hydrocortisone } & $44(44 \%)$ & $27(57.5 \%)$ & $22(32.1 \%)$ & 0.160 \\
\hline & Mean \pm s.D. & Mean \pm s.D. & Mean \pm s.D. & \\
\hline Duration of disease (years) & $14.7 \pm 11.6$ & $14.8 \pm 11.5$ & $14.5 \pm 11.9$ & 0.891 \\
\hline Age (years) & $49.7 \pm 22.1$ & $49.9 \pm 22.2$ & $49.5 \pm 21.9$ & 0.874 \\
\hline \multicolumn{5}{|l|}{ Anthropometric parameters } \\
\hline BMI $\left(\mathrm{kg} / \mathrm{m}^{2}\right)$ & $26.6 \pm 5.1$ & $25.9 \pm 5.3$ & $27.1 \pm 4.9$ & 0.329 \\
\hline Waist circumference $(\mathrm{cm})$ & $95.5 \pm 14$ & $95 \pm 14$ & $96 \pm 15$ & 0.639 \\
\hline Systolic blood pressure (SBP) (mmHg) & $113 \pm 15$ & $110 \pm 14$ & $116 \pm 16$ & 0.066 \\
\hline Diastolic blood pressure (DBP) (mmHg) & $69 \pm 9$ & $68 \pm 8$ & $70 \pm 9$ & 0.286 \\
\hline \multicolumn{5}{|l|}{ Electrolytes } \\
\hline $\mathrm{Na}(\mathrm{mmol} / \mathrm{L})$ & $138 \pm 4$ & $140 \pm 2$ & $137 \pm 4$ & 0.001 \\
\hline $\mathrm{K}(\mathrm{mmol} / \mathrm{L})$ & $4.7 \pm 0.6$ & $4.8 \pm 0.4$ & $4.5 \pm 0.5$ & 0.145 \\
\hline \multicolumn{5}{|l|}{ Metabolic parameters } \\
\hline Total cholesterol (mmol/L) & $5.22 \pm 1.04$ & $5.01 \pm 0.75$ & $5.30 \pm 1.1$ & 0.160 \\
\hline $\mathrm{HDL}$ cholesterol (mmol/L) & $1.53 \pm 0.48$ & $1.61 \pm 0.47$ & $1.41 \pm 0.52$ & 0.250 \\
\hline Triglycerides (mmol/L) & $1.50 \pm 0.71$ & $1.41 \pm 0.76$ & $1.56 \pm 0.67$ & 0.364 \\
\hline LDL cholesterol (mmol/L) & $2.89 \pm 0.92$ & $2.64 \pm 0.90$ & $3.04 \pm 0.91$ & 0.062 \\
\hline Fasting glycaemia (mmol/L) & $5.46 \pm 3.13$ & $5.40 \pm 3.2$ & $5.51 \pm 3.12$ & 0.886 \\
\hline $\mathrm{HbA} 1 \mathrm{c}(\mathrm{mmol} / \mathrm{mol})$ & $41.3 \pm 20.2$ & $34.9 \pm 21.6$ & $47.4 \pm 17$ & 0.002 \\
\hline
\end{tabular}

value between patients in group A and B at baseline.

$(P<0.001)$, HbA1c $(P=0.028)$ and higher values of HDL-C $(P=0.015)$ were observed in group B compared to group A (Table 4).

With regard to cardiovascular risk estimated by FRS, in non-diabetic patients a significant increase in group A $(P=0.002)$ and a significant decrease in group B $(P=0.015)$ was observed (Fig. 2A). On the other hand, for patients with type 2 diabetes mellitus, a significant decrease in the UKPDS risk engine $(P=0.002)$ was observed in patients in group $B$, while no change was shown in patients in group A (Fig. 2B).

No differences between patients switched from HC to DR-HC and patients switched from cortisone acetate to DR-HC were observed at baseline (data not shown).

The comparison between high and low doses of conventional GCs and DR-HC at 48 months of observation showed no significant differences for all parameters (Table 5).

\section{Patients with diabetes}

In the total sample of patients analyzed, ten (four in group A and six in group B) had type 1 diabetes mellitus. After 48 months of treatment, an increase in total daily and basal insulin (U/day) was observed in group A (Fig. 3A and B). By contrast, a decrease in total daily and basal insulin (U/day) was observed in group B (Fig. 3C and D).

With regard to type 2 diabetes mellitus, after 48 months of observation, three new cases of type 2 diabetes occurred in group A, with a total of seven patients. In three cases in group $\mathrm{A}$ the antidiabetic treatment was changed (in two patients liraglutide was added to metformin and in one patient sitagliptin was added to metformin). In group $\mathrm{B}$ no new cases of diabetes occurred and no change in antidiabetic treatment was observed.

In patients with type 2 diabetes mellitus in group B a decrease in BMI, WC, TC, LDL-C, fasting glycaemia 
Table 4 Anthropometric and metabolic parameters in groups A and B at baseline and after 48 months of treatment.

\begin{tabular}{|c|c|c|c|c|c|c|c|}
\hline & \multicolumn{2}{|c|}{ Group A (No. = 47) } & \multirow[b]{2}{*}{$\boldsymbol{P}^{\mathbf{a}}$} & \multicolumn{2}{|c|}{ Group B (No. = 53) } & \multirow[b]{2}{*}{$\mathbf{P}^{\mathbf{b}}$} & \multirow[b]{2}{*}{$\mathbf{P c}$} \\
\hline & $\begin{array}{l}\text { Baseline } \\
\text { Mean } \pm \text { S.D. }\end{array}$ & $\begin{array}{l}48 \text { months } \\
\text { Mean } \pm \text { S.D. }\end{array}$ & & $\begin{array}{c}\text { Baseline } \\
\text { Mean } \pm \text { S.D. }\end{array}$ & $\begin{array}{l}48 \text { months } \\
\text { Mean } \pm \text { S.D. }\end{array}$ & & \\
\hline \multicolumn{8}{|l|}{ Anthropometric parameters } \\
\hline $\mathrm{BMI}\left(\mathrm{kg} / \mathrm{m}^{2}\right)$ & $25.9 \pm 5.3$ & $28 \pm 5.47$ & $<0.001$ & $27.6 \pm 4.96$ & $26.6 \pm 5.06$ & 0.002 & 0.174 \\
\hline WC $(\mathrm{cm})$ & $94 \pm 13.5$ & $100 \pm 12$ & 0.001 & $98 \pm 13$ & $94 \pm 12$ & 0.015 & 0.020 \\
\hline Systolic blood pressure (mmHg) & $111 \pm 14$ & $121 \pm 14$ & 0.001 & $118 \pm 15$ & $115 \pm 16$ & 0.461 & 0.037 \\
\hline Diastolic blood pressure $(\mathrm{mmHg})$ & $68 \pm 8$ & $70 \pm 10$ & 0.251 & $71 \pm 9$ & $66 \pm 9$ & 0.031 & 0.162 \\
\hline \multicolumn{8}{|l|}{ Metabolic parameters } \\
\hline Total cholesterol (mmol/L) & $5.01 \pm 0.75$ & $5.07 \pm 0.71$ & 0.136 & $5.45 \pm 1.31$ & $4.72 \pm 0.72$ & 0.006 & 0.006 \\
\hline HDL cholesterol (mmol/L) & $1.56 \pm 0.54$ & $1.45 \pm 0.33$ & 0.137 & $1.52 \pm 0.48$ & $1.58 \pm 0.39$ & 0.284 & 0.015 \\
\hline Triglycerides (mmol/L) & $1.41 \pm 0.76$ & $1.48 \pm 0.72$ & 0.131 & $1.60 \pm 0.76$ & $1.47 \pm 0.83$ & 0.393 & 0.751 \\
\hline LDL cholesterol (mmol/L) & $2.64 \pm 0.9$ & $3.03 \pm 0.76$ & 0.018 & $3.08 \pm 0.99$ & $2.46 \pm 0.69$ & 0.005 & $<0.001$ \\
\hline $\mathrm{HbA} 1 \mathrm{c}(\mathrm{mmol} / \mathrm{mol})$ & $34.8 \pm 22.8$ & $43.1 \pm 10.4$ & 0.020 & $48.7 \pm 16.9$ & $39.1 \pm 8.9$ & $<0.001$ & 0.028 \\
\hline Fasting glycemia (mmol/L) & $5.45 \pm 3.22$ & $5.47 \pm 2.57$ & 0.960 & $5.65 \pm 3.57$ & $5.42 \pm 3.51$ & 0.549 & 0.225 \\
\hline
\end{tabular}

aP: comparison between baseline and 48 months of treatment in group A; ${ }^{b} P$ : comparison between baseline and 48 months of treatment in group $B$; ${ }^{c} P$ : comparison between groups $\mathrm{A}$ and $\mathrm{B}$ at 48 months of treatment.

and $\mathrm{HbA1c}$ was observed from baseline to 48 months of treatment (Fig. 4), while no differences were observed in patients in group A (data not shown).

\section{Patients lost to follow-up}

Of the total of ten patients lost to follow-up, six were on conventional GC treatment and four were on DR-HC. One patient on conventional GC treatment was followed up for 12 months, 2 patients for 18 months and the other 3 patients for 24 months. Among patients treated with DR-HC, two patients were followed up for 6 months, one patient for 12 months and the other one for 18 months.

The reasons for loss of follow-up in the group of conventional GCs were moving to another city for five out of six patients, while one patient died. In the DR-HC group, two patients moved to another city, while the other two experienced severe fatigue, vomiting and hypotension. These two patients were treated with an additional dose of $10 \mathrm{mg}$ of $\mathrm{HC}$ in the morning.

\section{Discussion}

This study shows that in patients with AI the innovative therapy with DR-HC is associated with an improvement in anthropometric and metabolic parameters and in cardiovascular risk expressed through the FRS during a 48-month period, compared to conventional GCs, which are associated with a worsening of metabolic profile and cardiovascular risk.

Conventional GC therapy has been reported to be associated with increased mortality and morbidity in patients with hypoadrenalism compared to the general population, likely due to negative effects on metabolism $(1,15,16,17,18)$. The effects of GCs on cardiovascular risk factors, such as obesity, hypertension, diabetes and dyslipidemia, are well known, as observed in hypercortisolism and in patients with AI on GC
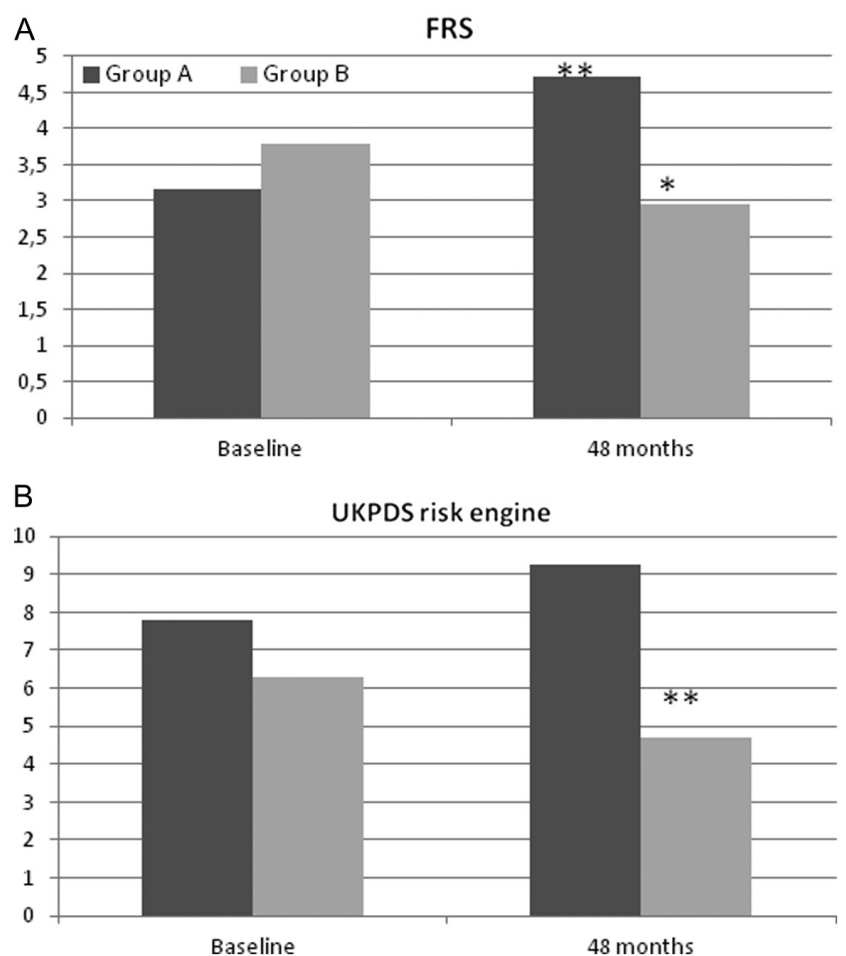

Figure 2

(A) Changes in FRS from baseline to 48 months for 74 non-diabetic patients of groups A and B. ${ }^{*} P<0.05, * * P<0.01 ; * \star * P<0.001$ vs baseline using the Student $t$ test. Data are means (S.D.). (B) Changes in UKPDS risk engine from baseline to 48 months for 14 patients with type 2 diabetes mellitus in groups A and B. $* P<0.05, * * P<0.01 ; * \star \star P<0.001$ vs baseline using the Student $t$ test. Data are means (S.D.).

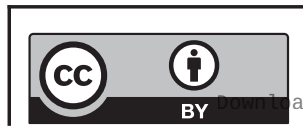

This work is licensed under a Creative Commons Attribution 4.0 International License. ded from Bioscientifica.com at 04/26/2023 10:25:28AM 
Table 5 Anthropometric and metabolic parameters in patients treated with high and low doses of conventional GCs after 48 months of treatment.

\begin{tabular}{l}
\hline \\
\hline Anthropometric parameters \\
BMI $\left(\mathrm{kg} / \mathrm{m}^{2}\right)$ \\
WC $(\mathrm{cm})$ \\
Systolic blood pressure $(\mathrm{mmHg})$ \\
Diastolic blood pressure $(\mathrm{mmHg})$ \\
Metabolic parameters \\
Total cholesterol (mmol/L) \\
HDL cholesterol (mmol/L) \\
Triglycerides (mmol/L) \\
LDL cholesterol (mmol/L) \\
HbA1c (mmol/mol) \\
Fasting glycemia (mmol/L) \\
FRS
\end{tabular}

\begin{tabular}{c}
\hline High doses of conventional GCs (No. $=16)$ \\
\hline Mean \pm S.D. \\
\\
$29.6 \pm 5.76$ \\
$103.3 \pm 13.6$ \\
$125 \pm 15$ \\
$71 \pm 10$ \\
\\
$5.42 \pm 0.66$ \\
$1.29 \pm 0.34$ \\
$1.33 \pm 0.44$ \\
$3.51 \pm 0.74$ \\
$42.3 \pm 9.34$ \\
$5.13 \pm 0.91$ \\
$5.03 \pm 4.39$
\end{tabular}

\begin{tabular}{|c|c|}
\hline Low doses of conventional GCs $($ No. $=31)$ & \\
\hline Mean \pm S.D. & $\mathbf{P}$ \\
\hline $27.5 \pm 5.21$ & 0.264 \\
\hline $99.5 \pm 11.5$ & 0.366 \\
\hline $119 \pm 13$ & 0.182 \\
\hline $68 \pm 9$ & 0.377 \\
\hline $5.19 \pm 0.80$ & 0.415 \\
\hline $1.37 \pm 0.32$ & 0.462 \\
\hline $1.61 \pm 0.79$ & 0.266 \\
\hline $3.05 \pm 0.73$ & 0.114 \\
\hline $44.8 \pm 12.8$ & 0.485 \\
\hline $5.74 \pm 3.01$ & 0.478 \\
\hline $4.26 \pm 3.36$ & 0.789 \\
\hline
\end{tabular}

replacement therapy $(19,20,21,22)$. However, discordant results are reported about the different effects of low and high doses of conventional GCs. Some studies have reported a dose-dependent association between oral GCs and the risk of cardiovascular and cerebrovascular disease (23), mainly due to endothelial dysfunction (24, 25). By contrast, other studies do not show an association between either cardiovascular function or cardiovascular risk factors with reduced daily doses of $\operatorname{HC}(2,26,27)$.

In the current study, no differences in metabolic parameters and cardiovascular risk were observed between high and low doses either in patients treated with conventional GCs or in patients treated with DR-HC. However, a trend of increase in BMI, WC, SBP, TC and LDL-C was observed in patients treated with high doses of DR-HC and need to be further evaluated in a larger cohort of patients. Interestingly, patients treated with low doses of both standard GCs and DR-HC tended to have a progressive increase of the dose during the observation period.

A hypothesis of the GC impact on cardiovascular risk may be that GCs act both directly through ample expression of GC receptors in the cardiovascular system, including blood vessel walls and myocardium (28), and indirectly through deterioration of glucose and lipid metabolism $(16,29,30)$.

The recent formulation of DR-HC has been shown to ensure an effective concentration of plasma cortisol, simulating the profile of physiological cortisol $(31,32)$. Several studies have shown that DR-HC treatment is associated with a reduction in weight, WC, systolic and diastolic blood pressure, HbA1c and lipids and an
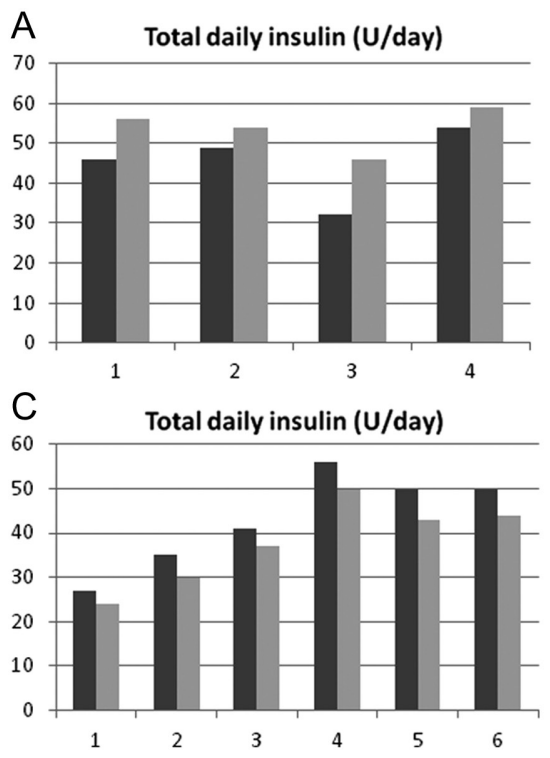
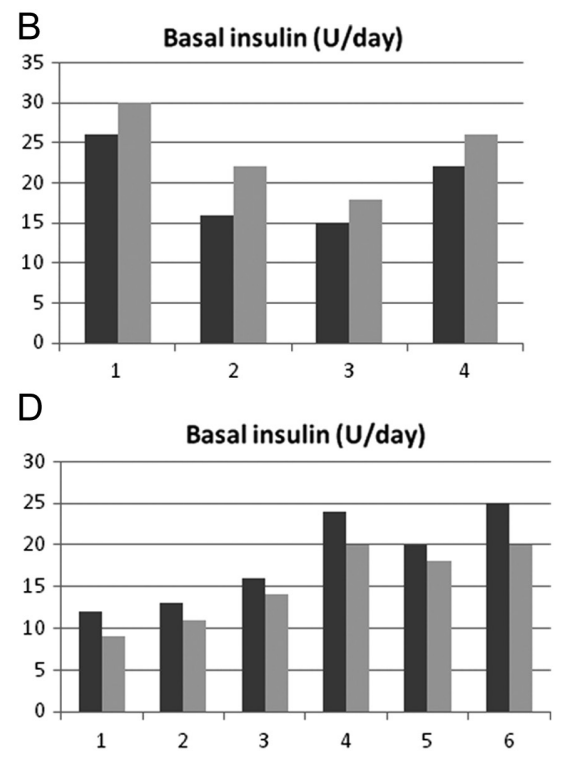

Figure 3

(A) Changes in total daily insulin (U/day) from baseline (dark gray line) to 48 months of treatment (light gray line) for four patients with type 1 diabetes mellitus in group A. (B) Changes in basal insulin (U/day) from baseline (dark gray line) to 48 months of treatment (light gray line) for four patients with type 1 diabetes mellitus in group A. (C) Changes in total daily insulin ( $U /$ day) from baseline (dark gray line) to 48 months of treatment (light gray line) for six patients with type 1 diabetes mellitus in group B. (D) Changes in basal insulin (U/day) from baseline (dark gray line) to 48 months of treatment (light gray line) for six patients with type 1 diabetes mellitus in group B. Data are single values for each patient. https://ec.bioscientifica.com https://doi.org/10.1530/EC-19-0176 (c) 2019 The authors Published by Bioscientifica Ltd

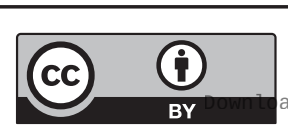

This work is licensed under a Creative Commons Attribution 4.0 International License. ded from Bioscientifica.com at 04/26/2023 10:25:28AM 

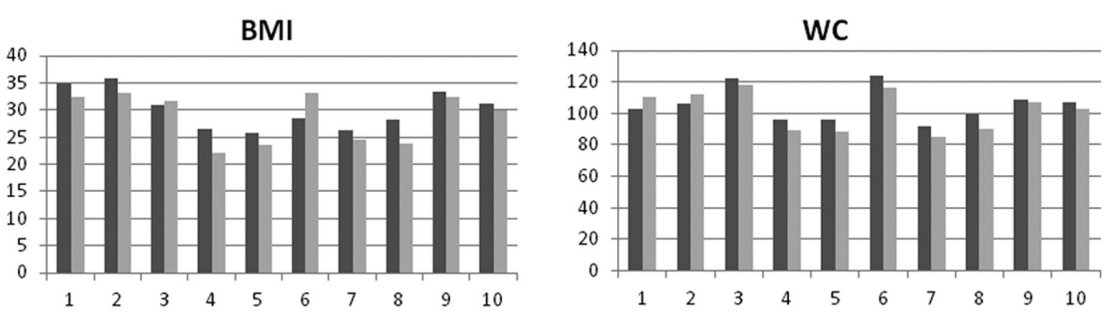

Total cholesterol
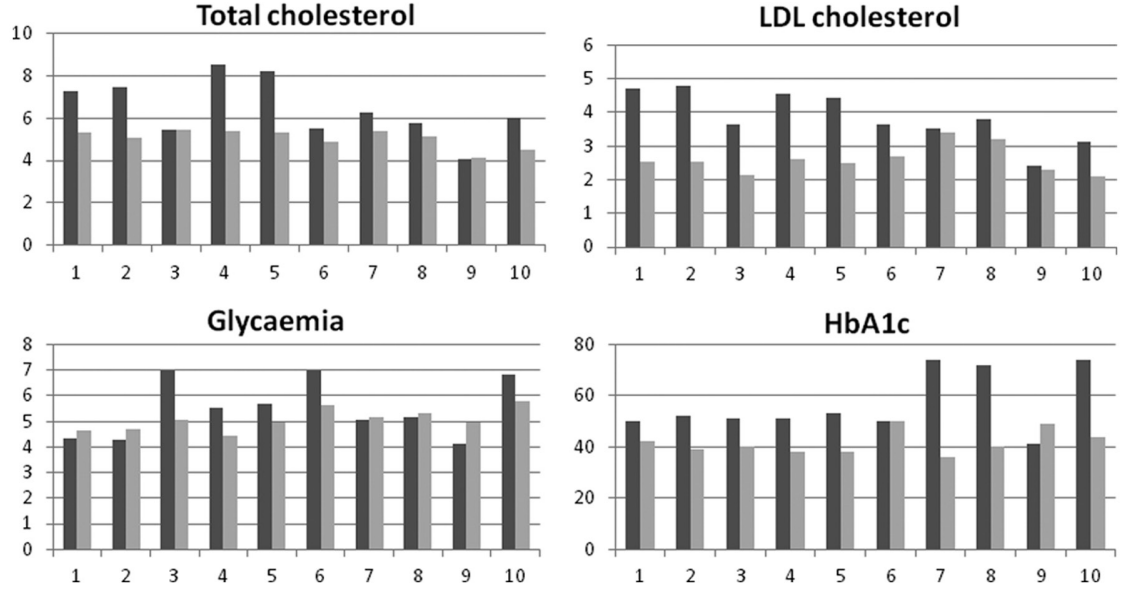

\section{Figure 4}

Changes in metabolic parameters from baseline (dark gray line) to 48 months of treatment (light gray line) for ten patients with type 2 diabetes mellitus in group B. BMI, body mass index; LDL, low density lipoprotein; WC, waist circumference. Data are single values for each patient. improvement of quality of life $(6,7,9,15)$. Furthermore, a recent study by our group documented a decrease in BMI, WC, HbA1c and an increase in HDL-C in patients treated with DR-HC for 36 months, showing a significant improvement in insulin secretion and sensitivity, even in patients with pre-diabetes (8).

In agreement with previous studies, in our study, we observed a significant worsening of BMI, WC and SBP, LDL cholesterol, HbA1c and FRS in patients treated with conventional GCs, while a significant improvement in DBP, BMI, WC, total and LDL cholesterol, HbA1c and FRS was observed in patients treated with DR-HC.

These findings are quite interesting because they show that cortisol-time exposure is strictly associated with a worsening of metabolism, likely influencing cardiovascular risk, even at low doses. Indeed, except for some patients (14 with cortisone acetate and 2 with hydrocortisone) treated with high doses of GCs, most of the patients on a conventional GC regimen were treated with low doses. In addition, in the group of patients treated with DR-HC, only one-third had high doses (35-40 mg/day). The findings of the current study suggest that the different profile of cortisol exposure, as in patients treated with DR-HC, may have an influence on metabolism and cardiovascular risk, more than the cumulative daily doses. Johansson et al. reported that switching from immediate-release hydrocortisone to DR-HC using the same total daily dose leads to a $22 \%$ reduction in cortisol exposure, as estimated by the area under the curve (31).
Therefore, the beneficial effects of DR-HC might be explained by a reduction in cortisol exposure, meaning more physiological circadian fluctuations of cortisol concentrations, from a relatively high and possibly immunosuppressive dose of conventional GCs to that equivalent to a standard replacement dose. Similarly, the large weight gain and consequent metabolic derangement in the group of patients treated with conventional GCs may be the effect of a prolonged exposure to supraphysiological cortisol levels.

The improvement in FRS in patients switched from conventional treatment to DR-HC is an interesting and innovative finding that may be explained by a reduction of GC exposure, notably overnight, and may be mediated by direct and indirect effects (improvement in anthropometric parameters, lipids and glucose metabolism).

In line with a previous study (7), we also found a decrease in insulin requirement in patients with type 1 diabetes mellitus treated with DR-HC, compared to an increase in those patients maintaining conventional GC therapy. Conventional GC therapy has already been reported negatively to affect insulin requirement in patients with APS and type 1 diabetes, compared to patients with only type 1 diabetes, mainly due to nonphysiological daily GC availability, notably in the evening, inducing an increase in insulin resistance $(33,34)$.

The improvement in BMI, WC, fasting glycemia, HbA1c, TC and LDL-C in patients with type 2 diabetes

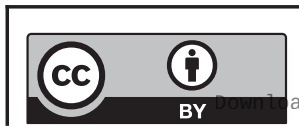

This work is licensed under a Creative Commons Attribution 4.0 International License. 
treated with DR-HC partially confirms the results of previous studies. Indeed, Giordano et al. showed an improvement in $\mathrm{HbA1c}$, but not in fasting glycaemia in diabetic patients treated with DR-HC (7). By contrast, Nilsson et al. did not show any differences in glucose control and lipid profile, except for an improvement in HDL-C, after a switch from conventional GCs to DR-HC (15). On the other hand, in our study, the maintenance of conventional GCs did not affect metabolism and anthropometric parameters, probably due to the addition of antidiabetic treatment in three out of four patients with type 2 diabetes mellitus.

The main limitations of the current study are the type of study, which is a real-world evidence-based one, and the small number of patients enrolled. Due to the rarity of the disease, a non-randomized design was chosen to evaluate as many patients as possible in the shortest possible time. However, this design introduces a selection bias and does not make it possible to control exposure or outcome assessment. Another limitation is that lifestyle, dietary habits, alcohol consumption, exercise and socioeconomic status were not verified. Although they are advised to increase the dose, we cannot be certain that patients will be compliant during the follow-up, due to the fear they frequently have of weight gain related to GC therapy. Lastly, the cohort of patients was quite heterogeneous (patients with PAI and SAI) and was characterized by different metabolic alterations, due to other hormonal deficiencies. Indeed in SAI, other pituitary deficiencies or replacement therapies, such as growth hormone, are to be considered as an additional risk factor for metabolic disorders.

However, all patients enrolled in the study were on stable replacement treatment and maintained good and stable hormonal control during the whole follow-up, thus not affecting, in our opinion, the outcomes of the study.

Despite these limitations, the strength of the study is represented by the long duration, the evaluation of cardiovascular risk and the inclusion of patients switched from cortisone acetate to DR-HC, which has not been widely described before.

In conclusion, our preliminary data, extracted from real-life clinical practice, suggest that 48-month treatment with DR-HC is associated with an improvement in anthropometric and metabolic parameters and cardiovascular risk, evaluated by FRS and the UKPDS risk engine, compared to conventional GC therapy, regardless of the dose used. However, further prospective studies performed in a larger cohort of patients are required in order to verify our data.

\section{Declaration of interest}

The authors declare that there is no conflict of interest that could be perceived as prejudicing the impartiality of the research reported.

\section{Funding}

This research did not receive any specific grant from any funding agency in the public, commercial or not-for-profit sector.

\section{Author contribution statement}

V G, C D, A S, A L C, A N C and C G had full control of the study design, data analysis and interpretation and preparation of the article. All authors were involved in planning the analysis and drafting the article. The final draft article was approved by all the authors.

\section{References}

1 Johannsson G, Falorni A, Skrtic S, Lennernäs H, Quinkler M, Monson JP \& Stewart PM. Adrenal insufficiency: review of clinical outcomes with current glucocorticoid replacement therapy. Clinical Endocrinology 201582 2-11. (https://doi.org/10.1111/cen.12603)

2 Bleicken B, Hahner S, Loeffler M, Ventz M, Decker O, Allolio B \& Quinkler M. Influence of hydrocortisone dosage scheme on healthrelated quality of life in patients with adrenal insufficiency. Clinical Endocrinology 201072 297-304. (https://doi.org/10.1111/j.13652265.2009.03596.x)

3 Kumari M, Badrick E, Ferrie J, Perski A, Marmot M \& Chandola T. Self-reported sleep duration and sleep disturbance are independently associated with cortisol secretion in the Whitehall II study. Journal of Clinical Endocrinology and Metabolism 200994 4801-4809. (https:// doi.org/10.1210/jc.2009-0555)

4 Johannsson G, Bergthorsdottir R, Nilsson AG, Lennernas H, Hedner T \& Skrtic S. Improving glucocorticoid replacement therapy using a novel modified-release hydrocortisone tablet: a pharmacokinetic study. European Journal of Endocrinology 2009161 119-130. (https:// doi.org/10.1530/EJE-09-0170)

5 Nilsson AG, Marelli C, Fitts D, Bergthorsdottir R, Burman P, Dahlqvist P, Ekman B, Engström BE, Olsson T, Ragnarsson $\mathrm{O}$ et al. Prospective evaluation of long-term safety of dual-release hydrocortisone replacement administered once daily in patients with adrenal insufficiency. European Journal of Endocrinology 2014171 369-377. (https://doi.org/10.1530/EJE-14-0327)

6 Quinkler M, Miodini Nilsen R, Zopf K, Ventz M \& Øksnes M. Modified-release hydrocortisone decreases BMI and HbA1c in patients with primary and secondary adrenal insufficiency. European Journal of Endocrinology 2015172 619-626. (https://doi.org/10.1530/ EJE-14-1114)

7 Giordano R, Guaraldi F, Marinazzo E, Fumarola F, Rampino A, Berardelli R, Karamouzis I, Lucchiari M, Manetta T, Mengozzi G, et al. Improvement of anthropometric and metabolic parameters, and quality of life following treatment with dual-release hydrocortisone in patients with Addison's disease. Endocrine 201651 360-368. (https://doi.org/10.1007/s12020-015-0681-z)

8 Guarnotta V, Ciresi A, Pillitteri G \& Giordano C. Improved insulin sensitivity and secretion in prediabetic patients with adrenal insufficiency on dual-release hydrocortisone treatment: a 36-month retrospective analysis. Clinical Endocrinology 201888 665-672. (https://doi.org/10.1111/cen.13554)

9 Mongioì LM, Condorelli RA, La Vignera S \& Calogero AE. Dualrelease hydrocortisone treatment: glycometabolic profile and healthrelated quality of life. Endocrine Connections 20187 211-219. (https:// doi.org/10.1530/EC-17-0368)

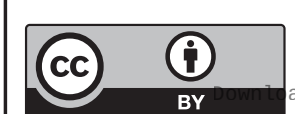

This work is licensed under a Creative Commons Attribution 4.0 International License. ded from Bioscientifica com at 04/26/2023 10:25:28AM 
10 Isidori AM, Venneri MA, Graziadio C, Simeoli C, Fiore D, Hasenmajer V, Sbardella E, Gianfrilli D, Pozza C, Pasqualetti P, et al. Effect of once-daily, modified-release hydrocortisone versus standard glucocorticoid therapy on metabolism and innate immunity in patients with adrenal insufficiency (DREAM): a single-blind, randomised controlled trial. Lancet: Diabetes and Endocrinology 20186 173-185. (https://doi.org/10.1016/S2213-8587(17)30398-4)

11 D'Agostino RB Sr, Vasan RS, Pencina MJ, Wolf PA, Cobain M, Massaro JM \& Kannel WB. General cardiovascular risk profile for use in primary care: the Framingham Heart Study. Circulation 2008117 743-753. (https://doi.org/10.1161/CIRCULATIONAHA.107.699579)

12 Stevens RJ, Kothari V, Adler AI, Stratton IM \& United Kingdom Prospective Diabetes Study (UKPDS) Group. The UKPDS risk engine: a model for the risk of coronary heart disease in Type II diabetes (UKPDS 56). Clinical Science 2001101 671-679. (https://doi. org/10.1042/cs1010671)

13 Bornstein SR, Allolio B, Arlt W, Barthel A, Don-Wauchope A, Hammer GD, Husebye ES, Merke DP, Murad MH, Stratakis CA, et al. Diagnosis and treatment of primary adrenal insufficiency: an Endocrine Society clinical practice guideline. Journal of Clinical Endocrinology and Metabolism 2016101 364-389. (https://doi. org/10.1210/jc.2015-1710)

14 American Diabetes Association. 2. Classification and diagnosis of diabetes: standards of medical care in diabetes-2018. Diabetes Care 201841 S13-S27. (https://doi.org/10.2337/dc18-S002)

15 Nilsson AG, Bergthorsdottir R, Burman P, Dahlqvist P, Ekman B, Engström BE, Ragnarsson O, Skrtic S, Wahlberg J, Achenbach H, et al. Long-term safety of once-daily, dual-release hydrocortisone in patients with adrenal insufficiency: a phase 3b, open-label, extension study. European Journal of Endocrinology 2017176 715-725. (https:// doi.org/10.1530/EJE-17-0067)

16 Malerbi D, Liberman B, Giurno-Filho A, Giannella-Neto D \& Wajchenberg BL. Glucocorticoids and glucose metabolism: hepatic glucose production in untreated Addisonian patients and on two different levels of glucocorticoid administration. Clinical Endocrinology 198828 415-422. (https://doi. org/10.1111/j.1365-2265.1988.tb03673.x)

17 Rafacho A, Ortsater H, Nadal A \& Quesada I. Glucocorticoid treatment and endocrine pancreas function: implications for glucose homeostasis, insulin resistance and diabetes. Journal of Endocrinology 2014223 R49-R62. (https://doi.org/10.1530/JOE-14-0373)

18 Debono M, Ross RJ \& Newell-Price J. Inadequacies of glucocorticoid replacement and improvements by physiological circadian therapy. European Journal of Endocrinology 2009160 719-729. (https://doi. org/10.1530/EJE-08-0874)

19 Harbeck B, Haas CS, Suefke S \& Moenig H. Cardiovascular risk factors and disease in patients with hypothalamic pituitary disorders. International Journal of Cardiology 2015184 464-465. (https://doi. org/10.1016/j.ijcard.2015.03.034)

20 Bergthorsdottir R, Ragnarsson O, Skrtic S, Glad CAM, Nilsson S, Ross IL, Leonsson-Zachrisson M \& Johannsson G. Visceral fat and novel biomarkers of cardiovascular disease in patients with Addison's disease: a case-control study. Journal of Clinical Endocrinology and Metabolism 2017102 4264-4272. (https://doi.org/10.1210/jc.201701324)

21 Giordano C, Guarnotta V, Pivonello R, Amato MC, Simeoli C, Ciresi A, Cozzolino A \& Colao A. Is diabetes in Cushing's syndrome only a consequence of hypercortisolism? European Journal of Endocrinology 2014170 311-319. (https://doi.org/10.1530/EJE-13-0754)

22 Guarnotta V, Amato MC, Pivonello R, Arnaldi G, Ciresi A, Trementino L, Citarrella R, Iacuaniello D, Michetti G, Simeoli C, et al.
The degree of urinary hypercortisolism is not correlated with the severity of Cushing's syndrome. Endocrine 201755 564-572. (https:// doi.org/10.1007/s12020-016-0914-9)

23 Souverein PC, Berard A, Van Staa TP, Cooper C, Egberts AC, Leufkens HG \& Walker BR. Use of oral glucocorticoids and risk of cardiovascular and cerebrovascular disease in a population based case-control study. Heart 200490 859-865. (https://doi.org/10.1136/ hrt.2003.020180)

24 Petersons CJ, Mangelsdorf BL, Thompson CH \& Burt MG. Acute effect of increasing glucocorticoid replacement dose on cardiovascular risk and insulin sensitivity in patients with adrenocorticotrophin deficiency. Journal of Clinical Endocrinology and Metabolism 201499 2269-2276. (https://doi.org/10.1210/jc.2013-4305)

25 Behan LA, Carmody D, Rogers B, Hannon MJ, Davenport C, Tormey W, Smith D, Thompson CJ, Stanton A \& Agha A. Lowdose hydrocortisone replacement is associated with improved arterial stiffness index and blood pressure dynamics in severely adrenocorticotrophin-deficient hypopituitary male patients. European Journal of Endocrinology $2016 \mathbf{1 7 4}$ 791-799. (https://doi.org/10.1530/ EJE-15-1187)

26 Dunne FP, Elliot P, Gammage MD, Stallard T, Ryan T, Sheppard MC \& Stewart PM. Cardiovascular function and glucocorticoid replacement in patients with hypopituitarism. Clinical Endocrinology 199543 623-629. (https://doi.org/10.1111/j.1365-2265.1995.tb02928.x)

27 Castinetti F, Sahnoun M, Albarel F, Morange I, Philippon M, Conte-Devolx B \& Brue T. An observational study on adrenal insufficiency in a French tertiary centre: real life versus theory. Annales d'Endocrinologie 201576 1-8. (https://doi.org/10.1016/j. ando.2014.11.004)

28 Walker BR. Glucocorticoids and cardiovascular disease. European Journal of Endocrinology 2007157 545-559. (https://doi.org/10.1530/ EJE-07-0455)

29 Arnaldi G, Scandali VM, Trementino L, Cardinaletti M, Appolloni G \& Boscaro M. Pathophysiology of dyslipidemia in Cushing's syndrome. Neuroendocrinology 201092 86-90. (https://doi. org/10.1159/000314213)

30 Ross IL, Bergthorsdottir R, Levitt NS, Schatz DA, Johannsson G \& Marais AD. Increased cardiovascular risk in South African patients with Addison's disease. Hormone and Metabolic Research 201345 905-910. (https://doi.org/10.1055/s-0033-1351259)

31 Johannsson G, Nilsson AG, Bergthorsdottir R, Burman P, Dahlqvist P, Ekman B, Engström BE, Olsson T, Ragnarsson O, Ryberg M, et al. Improved cortisol exposure-time profile and outcome in patients with adrenal insufficiency: a prospective randomized trial of a novel hydrocortisone dual-release formulation. Journal of Clinical Endocrinology and Metabolism 201297 473-481. (https://doi. org/10.1210/jc.2011-1926)

32 Johannsson G, Lennernas H, Marelli C, Rockich K \& Skrtic S. Achieving a phyisiological cortisol profile with once-daily dualrelease hydrocortisone: a pharmacokinetic study. European Journal of Endocrinology 2016175 85-93. (https://doi.org/10.1530/EJE-15-1212)

33 Elbelt U, Hahner S \& Allolio BL. Altered insulin requirement in patients with type 1 diabetes and primary adrenal insufficiency receiving standard glucocorticoid replacement therapy. European Journal of Endocrinology 2009160 919-924. (https://doi.org/10.1530/ EJE-08-1003)

34 Plat L, Leproult R, L'Hermite-Baleriaux M, Fery F, Mockel J, Polonsky KS \& Van Cauter E. Metabolic effects of short-term elevations of plasma cortisol are more pronounced in the evening than in the morning. Journal of Clinical Endocrinology and Metabolism 199984 3082-3092. (https://doi.org/10.1210/jcem.84.9.5978) https://ec.bioscientifica.com https://doi.org/10.1530/EC-19-0176 (c) 2019 The authors Published by Bioscientifica Ltd
Received in final form 13 May 2019

Accepted 4 June 2019

Accepted Preprint published online 4 June 2019 